\title{
Spatial Pattern Analysis of Citrus Canker-Infected Plantings in São Paulo, Brazil, and Augmentation of Infection Elicited by the Asian Leafminer
}

\author{
T. R. Gottwald, R. B. Bassanezi, L. Amorim, and A. Bergamin-Filho
}

First author: United States Department of Agriculture-Agricultural Research Service, Ft. Pierce, FL 34945; second author: Fundecitrus 14807-040, Araraquara, SP, Brazil; and third and fourth authors: Departamento de Entomologia, Fitopatologia e Zoologia Agrícola, Escola Superior de Agricultura Luiz de Queiroz, Universidade de São Paulo, 13418-900, Piracicaba, SP, Brazil. Accepted for publication 11 January 2007.

\begin{abstract}
Gottwald, T. R., Bassanezi, R. B., Amorim, L., and Bergamin-Filho, A. 2007. Spatial pattern analysis of citrus canker-infected plantings in São Paulo, Brazil, and augmentation of infection elicited by the Asian leafminer. Phytopathology 97:674-683.

Eradication of Asiatic citrus canker (ACC) has become increasingly difficult over the last decade, following the introduction of the Asian leafminer into Brazil and Florida, which has led to changes in the eradication protocols. The present study, undertaken in Brazil, was aimed at characterizing the spatial patterns of ACC in commercial citrus plantings to gain better understanding of the dynamics of the disease subsequent to introduction of the leafminer. The spatial patterns of ACC were mapped in 326 commercial citrus plantings and statistically assessed at various spatial dimensions. The presence of "within-group" aggregation in each plot was examined via $\beta$-binomial analysis for groups of trees parsed into three-by-three-tree quadrats. The relative intensity of aggregation was expressed as a binomial index of dispersion $(D)$ and heterogeneity among plots expressed as the intracluster correlation coefficient, $\rho$. The population of data sets was found to fall into three $D$ categories, $D<1.3,1.3 \leq D=3.5$, and $D>3.5$. These categories then were related to other spatial characteristics. The binary form of Taylor's power law was used to assess the overdispersion of disease across plots and was highly significant. When the overall population of plots was parsed into $D$ categories, the Taylor's $R^{2}$ improved in all cases. Although these methods assessed aggregation well, they do not give information on the number of foci or aggregations within each plot. Therefore, the number of foci per 1,000 trees was quantified and found to relate directly
\end{abstract}

ABSTRACT

Xanthomonas axonopodis pv. citri causes Asiatic citrus canker (ACC) in the majority of commercial citrus production regions of the world. ACC is characterized by erumpent lesions on fruit, foliage, and young stems of susceptible cultivars of citrus. When disease is severe, defoliation, dieback, and fruit drop can occur and remaining infected fruit have marginal or no marketability $(12,19,29)$. When rain is combined with wind speeds in excess of $8 \mathrm{~m} / \mathrm{s}$, numerous new infections can result from rain-splashed inoculum and resulting symptoms can be severe (38). To prevent the introduction of the disease, many citrus-growing areas restrict the importation of citrus from areas or countries known to have

Corresponding author: T. R. Gottwald;

E-mail address: Tim.Gottwald@ARS.USDA.GOV

\section{doi:10.1094/PHYTO-97-6-0674}

This article is in the public domain and not copyrightable. It may be freely reprinted with customary crediting of the source. The American Phytopathological Society, 2007. to the $D$ categories. The lowest $D$ category could be explained by a linear relationship of number of foci versus disease incidence, whereas the higher two categories were most easily explained by a generalized $\beta$ function for the same relationship. Spatial autocorrelation then was used to examine the spatial relationships "among groups" composed of threeby-three-tree quadrats and determine common distances between these groups of ACC-infected trees. Aggregation was found in $>84 \%$ of cases at this spatial level and there was a direct relationship between increasing $D$ category and increasing core cluster size, and aggregation at the amonggroup spatial hierarchy was generally stronger for the within-row than for the across-row orientation. Clusters of disease were estimated to average between 18 and 33 tree spaces apart, and the presence of multiple foci of infection was commonplace. The effectiveness of the eradication protocol of removing all "exposed" trees within $30 \mathrm{~m}$ surrounding each "ACCinfected tree" was examined, and the distance of subsequent infected trees beyond this $30-\mathrm{m}$ zone from the original focal infected tree was measured for each plot. A frequency distribution was compiled over all plots to describe the distance that would have been needed to circumscribe all of these outliers as a theoretical alternative protocol to the $30-\mathrm{m}$ eradication protocol. The frequency distribution was well described by a monomolecular model $\left(R^{2}=0.98\right)$ and used to determine that 90,95 , and $99 \%$ of all newly infected trees occurred within 296,396 , and $623 \mathrm{~m}$ of prior-infected trees in commercial citrus plantings, respectively. These distances are very similar to previously reported distances determined for ACC in residential settings in Florida.

Additional keywords: exposed trees. endemic canker. Citrus canker existed in São Paulo (Brazil) and Florida prior to the introduction of the Asian leafminer, Phyllocnistis citrella. Introduction of the leafminer to São Paulo in 1996 and to Florida in 1993 exacerbated citrus canker, and changed the dynamics of the existing eradication programs in these areas. The severity of ACC increased as a consequence of the insect's feeding activities, which expose leaf mesophyll tissues and increase the probability of infection by $X$. axonopodis pv. citri (11). Leafminer larvae form feeding galleries in the epidermal cell layer of young leaves and other tissues, lifting and eventually tearing the cuticle and opening the mesophyll of the leaf to direct bacterial infection when splash-dispersed or windblown-rain-dispersed bacteria come in contact with the leaf surface $(20,21)$. Also, the leafminer larvae may become contaminated with bacteria and transport them through the feeding galleries, resulting in numerous mesophyll infections (20). As these numerous lesions within the feeding gallery expand, they rupture through the epidermis and coalesce to form massive infections covering large areas of the leaf lamina. This serves to greatly in- 
crease the infected foliar area and generates many times the amount of inoculum compared with $X$. axonopodis pv. citri infections where the leafminer is not present (20). When wetted, large amounts of inoculum exude from the numerous leafminer-induced lesions, which can be spread by rain splash, thus accelerating the epidemic. Studies to determine whether the leafminer can act directly as a vector for $X$. axonopodis pv. citri have all been negative (1).

ACC has caused epidemics in various citrus-producing countries in South America, including Argentina, Bolivia, Brazil, Chile, Paraguay, and Uruguay (4,29). Argentina, Brazil, and Uruguay started eradication programs soon after disease discovery. Argentina discontinued the eradication program in the provinces of Entre Rios and Corrientes in 1979 because commercial growers felt that the loss of citrus due to eradication was endangering the entire industry; however, Argentina maintained "cankerfree" zones in the northwestern Provinces of Salta, Jujuy, and Tucumán for export purposes which continue until today (25). Uruguay and Brazil continue to enforce an eradication program (11).

Canker first affected the Florida citrus industry in 1910, but was eradicated by the 1930s after massive removals of infected trees (37). ACC was discovered a second time in Florida in 1986 and was declared eradicated in 1992, but was discovered a third time in Florida in residential citrus in Dade County in 1995 and subsequently spread to the majority of the counties in the southern half of the state via a combination of human and natural spread (13).

The scientific basis for Brazil's eradication effort was provided by data from Argentina indicating that canker bacteria could be recovered on plants up to $30 \mathrm{~m}(98 \mathrm{ft})$ downwind from an infected source following rainstorms associated with wind (41). Until recently in Brazil, citrus trees within a 30-m radius of an infected tree were considered to be exposed and were removed in an attempt to achieve eradication. However, this approach appeared to lose its effectiveness after 1997 and, in 1999, Brazil changed its policy, basing the eradication program on both distance from diseased trees and disease incidence, such that if disease incidence is $\leq 0.005$, then the $>30$ - $\mathrm{m}$ eradication strategy is used. However, if disease incidence is $>0.005$, then all trees within the infected block (defined as a planting of consistent cultivar and age) are destroyed.

Until recently, Florida used a similar but slightly greater distance, $38.1 \mathrm{~m}$ (125 ft), to define exposed trees for removal (both from commercial plantings and in residential areas). However, after the introduction of the Asian leafminer, Florida also found it inadequate to suppress the disease's increase and to curtail its further spread in urban areas, and the disease subsequently spread to numerous commercial citrus plantations across south Florida $(12,17)$. At the request of the Citrus Canker Eradication Program (CCEP), a study was undertaken to examine the appropriateness and effectiveness of the 125 -ft rule. Based on this study, Federal and State scientists determined the distance to achieve eradication to be $561 \mathrm{~m}(1,900 \mathrm{ft})$. The Florida Commissioner of Agriculture implemented the " $1,900-\mathrm{ft}$ rule" in January 2000, and it subsequently became a Florida statute (13, 15,17). Between 1994 and January 2006, over 7 million commercial, 844,327 residential, and 4.2 million nursery trees were destroyed in an attempt to eradicated ACC in Florida. By early 2006, the effect of the 2004 and 2005 hurricanes that crisscrossed the Florida peninsula had greatly exacerbated and spread citrus canker, increasing the disease incidence and distribution to the point that eradication was no longer considered to be feasible; therefore, the eradication program was discontinued.

Epidemiological studies on citrus canker have been conducted in endemic environments and concentrated on local disease increase and spread of $X$. axonopodis pv. citri mostly within citrus research nurseries and plantings and within only a few comercial plantations $(6,14,18,35,40)$. In citrus nurseries in Argentina prior to the introduction of the leafminer, dissemination of $X$. axonopodis pv. citri was primarily by splash dispersal (18). The result was the development of numerous secondary foci that eventually coalesce into larger, irregularly shaped areas of disease. Slopes of disease gradients associated with ACC in nurseries fluctuated over time because of disease-induced defoliation on severely diseased nursery plants and infection of newly emerging foliage (18). Highly significant aggregation of citrus canker-infected trees was associated with splash dispersal, which decreased as the secondary foci coalesced, and this aggregation was slightly higher within nursery rows than across nursery rows (18).

Slopes of ACC disease gradients in citrus orchards in Argentina prior to the introduction of the leafminer also fluctuated in response to disease-induced defoliation. However, unlike citrus nurseries, gradient slopes were related to windblown rain direction (14), and aggregation of diseased trees was indicated throughout the epidemics (14).

Spatial autocorrelation and spatio-temporal (ST) autocorrelation methods have been used to examine the spread of citrus canker in nurseries and orchards through time prior to the occurrence of the leafminer (15) to examine the evolution of an epidemic in both space and time simultaneously $(34,36)$. The results of ST autocorrelation analysis led to the description of an ST transfer function in the form of a mixed ST autoregressive integrated moving average (STARIMA) model that demonstrated disease relationships that persisted through one or more spatial or temporal lags (15).

In Florida, where citrus canker is an exotic disease and was under eradication until recently, the opportunities to examine the epidemiology of the disease have been infrequent and involve rapid assessment of disease during the short interval between discovery of disease and eradication of the trees. One such study occurred in 1990 in a commercial orchard in south Florida (10). The focus of infection was determined to be three 8- to 10-yearold lemon trees in a rural home site that predated the planting of a large commercial orange orchard immediately to the west. An August 1989 rainstorm with associated high winds resulted in dissemination of inoculum and the establishment of four foci of infection in the orange orchard that ranged from 230 to $810 \mathrm{~m}$ ( 755 to $2,657 \mathrm{ft}$ ) from the infected home site source trees. This was the first documented spread of citrus canker over such great distances associated with rainstorms but was prior to the introduction of the Asian leafminer (10).

The studies on which the Florida 1,900-ft law was based were conducted in five areas in urban Miami, subsequent to introducetion of the Asian leafminer, and were done to provide accurate information on the spread of $X$. axonopodis pv. citri for the development of biologically sound and effective eradication or suppression procedures under urban conditions (17). Distances between each newly diseased tree and all prior-infected trees were calculated. Among the five study areas, distances of spread ranged from 12 to $3,474 \mathrm{~m}$, indicating that a broad continuum of distance for bacterial spread was possible. Even though new lesions can be seen with the naked eye 7 to 10 days after infection, cross-correlation analysis indicated that disease was best visualized by inspectors under urban field conditions 107 days following rainstorms with wind (17). The results of this study were examined by a group of scientists, regulators, and citrus producers familiar with the disease. Based on measurements of disease spread, they selected a distance of $579 \mathrm{~m}(1,900 \mathrm{ft})$ as a radius that would encompass the majority of newly infected trees resulting from a prior infection focus that can occur within a 30-day period. The study and the resulting determination of the 579-m distance served as the scientific basis of the eradication of exposed trees around foci of infection practiced in Florida until eradication was discontinued in early 2006 (17).

Previous studies on the increase and spread of ACC have been conducted in Argentina and Florida; however, these have been 
predominantly in research plots or in urban settings, and only one study has described the spatial patterns of citrus canker in a single commercial setting (10). No formal studies have been conducted on the epidemiological aspects of ACC in multiple commercial plantings following the introduction of the Asian leafminer. The present ACC epidemic in São Paulo, Brazil, has provided numerous opportunities to collect and examine spatial data in commercial plantings. This collection of spatial data sets were examined to elucidate the spatial pattern and spread of $X$. axonopodis pv. citri for the development of biologically sound and effective eradication or suppression procedures under commercial conditions in São Paulo. In Brazil, as in Florida, due to citrus canker eradication policy, temporal assessments of the disease under commercial settings are not possible. This report represents the first detailed study of the spatial and ST distribution of citrus canker in commercial groves afflicted with Asian leafminer; therefore, the results can be compared with previous reports of disease distribution prior to introduction of the leafminer.

The objectives of the studies were to (i) examine and describe the spatial heterogeneity of ACC in commercial plantings infested with leafminer in São Paulo, (ii) determine the distance of spread from source of infection in these commercial plantings and thus evaluate the effectiveness of the $30-\mathrm{m}$ eradication policy, and (iii) provide evidence for any adjustment of radius distance that would more effectively define the distance of bacterial spread in regions like São Paulo, Brazil, where the Asian leafminer now exists.

\section{MATERIALS AND METHODS}

In collaboration with the citrus canker eradication program in São Paulo, spatial maps of ACC-infected and noninfected trees were collected from 326 commercial citrus plantings composed of 91,6 , and $3 \%$ orange, tangerine, and lime cultivars, respectively, all moderately susceptible to ACC. All plantings were susceptible to and subjected to leafminer infestation because the insect was endemic at the time of mapping and the infestation was moderate to severe across the region during the time of data collection, and more or less uniform in distribution. The maps were examined at two spatial scales to assess their spatial structure. For calculation of the dispersal index $(D)$, and for $\beta$-binomial distribution (BBD) and spatial autocorrelation analyses, maps of ACC incidence were parsed into three-by-three trees per quadrat $(n=9)$.

Binary form of Taylor's power law. This method was used as an assessment of overdispersion within sampling unit (quadrat) across all 326 ACC data sets. For disease incidence data, the binary power law (26) expresses the relationship between the observed sample variance of diseased trees within sampling units $\left(\mathrm{V}_{\mathrm{obs}}\right)$ and the theoretical variance of random distribution $\left(\mathrm{V}_{\text {bin }}\right)$; that is, the binomial variance for binary data $\{n p[1-p]\}$ when $n$ is the group size or number of trees per quadrat and $p$ is the mean disease incidence. It can be written as:

$$
\log \left(\mathrm{V}_{\text {obs }}\right)=\log (A)+b \log \left(\mathrm{V}_{\text {bin }}\right)
$$

in which $\log (A)$ and $b$ are the intercept and the slope of a straight line, respectively. When both $A$ and $b$ are equal to 1 , then a random spatial pattern is suggested and best described by the binomial distribution. When $b=1$ and $A>1$, there is overdispersion with no dependence on the mean incidence $p$. When both $A$ and $b$ are $>1$, the degree of aggregation varies with $p$. The parameters $\log (A)$ and $b$ were estimated by linear regression using the least squares method. The equality of $\log (A)$ to 0 and $b$ to 1 were tested by a $t$ test using the estimates of the parameter and its standard deviation.

BBD analysis. The binomial distribution is the most appropriate to describe a random pattern of disease incidence at the quadrat scale, whereas the $\mathrm{BBD}$ is more appropriate for an aggregated pattern (27). Using the BBD program (30), the maximum likelihood estimates and standard errors of the parameters $\mathrm{p}$ (i.e., the expected probability of disease) and $\theta$ (the measure of the variation in disease incidence per sampling unit) of the BBD were calculated. When $\theta$ is close to 0 , the $\beta$-binomial is reduced to the binomial distribution (32). Theta $(\theta)$ is the aggregation parameter of the distribution and is a measure of the variation in disease incidence per quadrat and a direct measure of heterogeneity when the $\beta$-binomial is appropriate. A $t$ test was used to determine if the maximum likelihood estimate of $\theta$ differed significantly from 0 . The measure of heterogeneity can be reparameterized as the intracluster correlation coefficient $\rho=$ $\theta /\{1+\theta\}$ (sometimes referred to as the intraclass correlation coefficient, $k$, when calculated as $k=(D-1) /(n-1)$, and results in nearly identical values), which ranges from 0 to 1 and is a measure of the tendency of individual plants within quadrats to have the same disease status when $n$ is not always constant (i.e., values closer to 0 indicate less variability of disease status) (31,33).

Binominal index of dispersion $(D) . D$ is defined as the ratio of the observed variance of diseased trees per sampling unit, $V_{\text {obs }}$, to the theoretical binomial variance, $\mathrm{V}_{\text {bin. }}$. Values of $D>1$ are considered indicative of aggregation. Calculations of $D$ were performed for each of the 326 ACC data sets. Values of $D>1$ suggested aggregation at or below the quadrat scale chosen $(n=9$ plants). To test for overdispersion, the $\chi^{2}$ statistic $(D[N-1]$ with $N-1$ degrees of freedom) was used and the $\mathrm{C}(\alpha)$ test given by

$$
\mathrm{C}(\alpha)=\frac{[(\mathrm{n} N-1) D-\mathrm{n} N]}{\left[2 N\left(\mathrm{n}^{2}-\mathrm{n}\right)\right]^{1 / 2}}
$$

which has a standard normal distribution under the null hypothesis of randomness. For this latter test, the alternative hypothesis is overdispersion described by the $\beta$-binomial (onesided test) (27).

Analysis of the number of foci per plot. Although the $\beta$ binomial analysis assesses aggregation, it does not determine whether aggregation is due to the presence of one or numerous foci within the plot. To estimate the number of foci, groups of infected plants contiguous with one another but discontinuous with other groups (foci) in each plot were counted, and the data were normalized (number of foci per 1,000 plants) within each ACC-infected plot. The number of foci per 1,000 trees was plotted versus disease incidence for all 326 data sets and fitted to a generalized $\beta$ function (24):

$$
Y=b_{1}(x)^{b 2} \times(1-x)^{b 3}
$$

where $y=$ the number of foci per 1,000 trees, $x$ is disease incidence, and $b_{1}, b_{2}$, and $b_{3}$ are calculated regression constants.

Spatial autocorrelation analysis. For the next level of spatial hierarchy, the strength and directionality or orientation of aggregation among quadrats containing symptomatic citrus trees were examined for each data set using spatial autocorrelation analysis (16). The $x, y$ spatial location and disease incidence of trees for each quadrat size on each assessment date in the individual citrus plots were used as input data. Autocorrelation proximity patterns were calculated consisting of positively (SL+), negatively (SL-), and noncorrelated lag positions from which an evaluation of spatial patterns of disease incidence was performed (16). The size and shape of core and reflected clusters of SL+ were calculated, in which a core cluster is a group of significant, positively correlated $(P=0.05)$, spatial lag distance classes that form a discrete and contiguous group with the origin (i.e., lag [0.0]) of the autocorrelation proximity pattern; a reflected cluster is a discrete group of two or more contiguous significant positive lag positions discontinuous with the origin and the core cluster. 
The strength of aggregation is a measure of the saturation of the core clusters with significantly positive lags (i.e., the proportion of lag positions within the extents of the cluster that were significantly positive). Row effects were evaluated as the number of significant lag positions within the first row (within) or within the first column (across) of the autocorrelation proximity pattern that are contiguous with the origin. Edge effects were considered significant if the proportion of SL+ positions at the distal edges of the proximity pattern were $>0.05$ (7).

Reoccurrence of ACC in plantings subjected to eradication. $X$. axonopodis pv. citri-infected trees continued to occur in São Paulo commercial plantings following eradication efforts. Posteradication maps of ACC-infected and noninfected trees were collected from 100 commercial plantings where citrus canker reoccurred following tree removal. The post-eradication maps were interrogated to determine the distance from previously identified and removed infected trees and new $X$. axonopodis $\mathrm{pv}$. citri-infected trees beyond the $30-\mathrm{m}$ radius of destruction used for eradication. The number of new $X$. axonopodis pv. citri-infected trees were parsed into the $30-\mathrm{m}$ frequency categories across all 100 data sets combined. The data then were plotted as the frequency of counts of diseased plants by distance and fitted by nonlinear regression to an inverse power law function:

$$
y=a_{1} \times x^{-a_{2}}
$$

where $y=$ disease incidence, $x=$ distance from previous $X$. axonopodis pv. citri-infected tree, and $a_{1}$ and $a_{2}$ are regression constants. The cumulative percentage of the total population (cumulative distribution function) of newly $X$. axonopodis $\mathrm{pv}$. citri-infected trees also was plotted over distance and the cumulative distribution function was fitted to a monomolecular model:

$$
y=1-\left\{b_{1} \times \exp \left[b_{2} \times x\right]\right\}
$$

where $y=$ cumulative percentage of disease population, $x=$ distance from previous $X$. axonopodis pv. citri-infected tree, and $b_{1}$ and $b_{2}$ are constants.

The results were compared with those previously published for citrus canker in urban south Florida (17). Using the same method as applied to the São Paulo commercial citrus data, the Florida data were formatted as a frequency of counts of diseased plants by distance and also as a cumulative distribution function and fitted to equations 4 and 5 above.

\section{RESULTS}

Binary form of the Taylor's power law. The relationship between $\log \left(\mathrm{V}_{\mathrm{obs}}\right)$ and $\log \left(\mathrm{V}_{\text {bin }}\right)$ was highly significant $\left(R^{2}=\right.$ $0.946, P=0.1455 \times 10^{-203}$ ) across all 321 data sets (Fig. 1A). Estimates of $b$ and $\log (A)$ were 1.211 and 0.8372 (standard error $=0.016$ and 0.043 ), respectively, for data parsed into nine-tree quadrats (Fig. 1A). The population of data sets also was examined relative to three categories defined by the magnitude of $D$ (i.e., $D$ $<1.3,1.3 \leq D \leq 3.5$, and $D>3.5$ ). The rational for the choice of $D$ magnitude categories is presented in the foci analyses below. Estimates of $b$ were $1.028,1.083$, and 1.143 and of $\log (A)$ were $0.116,0.504$, and 0.913 with $R^{2}$ values of $0.980,0.955$, and 0.950 , for the categories $D<1.3,1.3 \leq D \leq 3.5$, and $D>3.5$, respectively, and all estimates were highly significant (Fig. 1BE). All estimates of $b$ and $A$ were statistically different from 1 , which indicated a general and significant pattern of aggregation of symptomatic plants within all three $D$ categories tested. All values of $b$ were $>1$, indicating that the degree of aggregation was a function of incidence. These results support those obtained with the $\beta$-binomial index of dispersion below (i.e., plants with citrus canker symptoms show aggregation throughout the range of disease incidence and aggregation intensifies with the increase of disease incidence).
BBD analysis and dispersal index. The first level of spatial hierarchy to be examined was the association of symptomatic plants within quadrats of various sizes. Of the 326 plots examined, the BBD program converged and produced output for 321. The interpretation of the values of the binomial index of dispersion $D$ suggests a spatial structure of symptomatic plants significantly nonrandom (i.e., aggregated) for 246/321 plots or $76.6 \%$ of the plots tested at the three-by-three-plant quadrat size, especially between incidence values of $>0.01$ and $<0.9$. The 321 plots were divided into three categories based on the magnitude of their individual $D$ value, $D<1.3,1.3 \leq D \leq 3.5$, and $D>3.5$, related to the foci analysis below. If we examine the $D$ values for the population of ACC-infected plots as a function of disease incidence, we see that disease incidence was $<0.1$ for the majority of the plots (Fig. 2A). If we examine the relationship of the $D$ value categories relative to disease incidence, we see that they are overlapping; however, for the first category, $D<1.3$, nearly all have disease incidence values $<0.08$ whereas, for the second
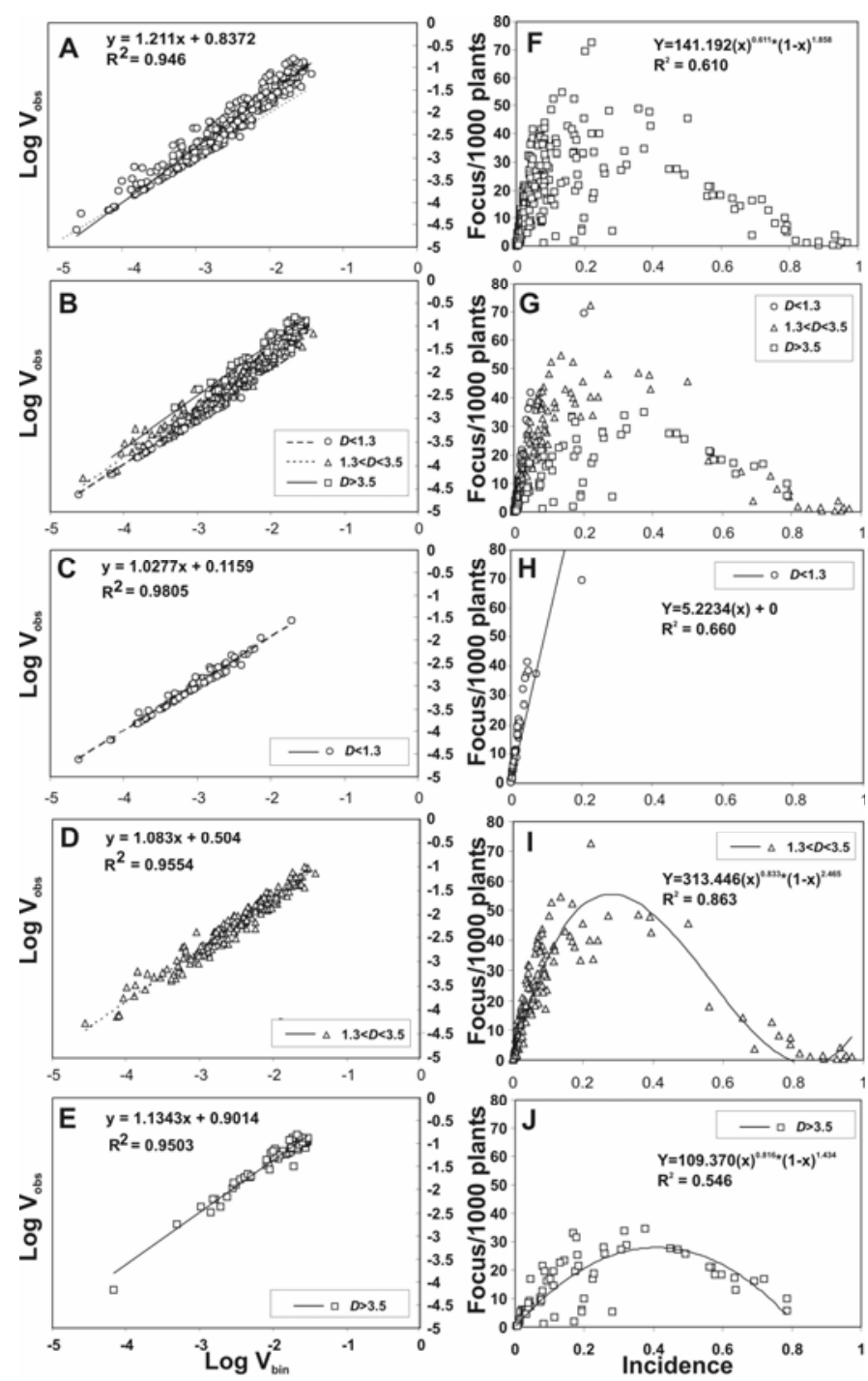

Fig. 1. Spatial analysis at the within-quadrat scale of 203 orchards infected with citrus canker in Sao Paulo state, Brazil. A, Overall relationship between $\log \left(\mathrm{V}_{\mathrm{obs}}\right)$ and $\log \left(\mathrm{V}_{\mathrm{bin}}\right)$ for the complete population of data sets. B-E, Relationship between $\log \left(\mathrm{V}_{\text {obs }}\right)$ and $\log \left(\mathrm{V}_{\text {bin }}\right)$ separated into individual data sets categorized by the dispersion index $D$ value $(D<1.3,1.3 \leq D \leq 3.5$, and $D$ $>3.5$ ). F, Relationship of the number of foci per 1,000 plants shown as a function of disease incidence for the complete population of data sets. G-J, Relationship of the number of foci per 1,000 plants separated into individual data sets categorized by the dispersion index $D$ value $(D<1.3,1.3 \leq D \leq 3.5$, and $D>3.5$ ). 
category $1.3 \leq D \leq 3.5$, the majority of disease incidence values fall $<0.1$ but span the full range of disease incidence, and the $D>$ 3.5 category spans nearly the full range of disease incidence and is not as associated with lower disease incidence values. These same trends are seen for the $\beta$-binomial $\theta$ parameter, the intraclass correlation coefficient $(k)$, and the intracluster correlation coefficient ( $\rho$ ) (Fig. 2B-D), as expected because of the direct relationships among $D, \theta$, and $k$ (Fig. $2 \mathrm{E}$ and $\mathrm{F}$ ).

Examination of the number of foci per orchard. The estimate of the number of foci per 1,000 trees was plotted against disease incidence and fitted to the generalized $\beta$ function as described above (Fig. 1F). The number of foci per 1,000 trees increased rapidly with disease incidence and peaked at a maximum of $73 / 1,000$ trees at a disease incidence of $\approx 0.22$. Above this point, the estimated number of foci tended to decline gradually with disease incidence. The foci per 1,000 trees also were examined relative to the three categories defined by the magnitude of $D$ (Fig. 1G-J). For the first category, $D<1.3$, the number of foci per 1,000 trees increased rapidly and the trend was described by a linear increase $\left(R^{2}=0.660\right)$ (Fig. $\left.1 \mathrm{H}\right)$. For the second category, $1.3 \leq D \leq 3.5$, the number of foci per 1,000 trees was described well $\left(R^{2}=0.863\right)$ by the generalized $\beta$ function and peaked at 73/1,000 trees and 0.22 disease incidence, the same as the overall population of orchards (Fig. 1I). For the third category, $D>3.5$, the trend was described by the generalized $\beta$ function but only $54.6 \%$ of the variation due to regression was accounted for by the $\beta$ function (Fig. 1I). For this last category, the peak in the number of foci was at 34/1,000 trees, at a disease incidence of 0.37, and did not extend beyond a disease incidence of 0.79 (Fig. 1J). Plot maps from representative orchards from each of the above $D$ categories are presented in Figure 3.

Spatial autocorrelation analyses. The second level of spatial hierarchy examined was the association among groups (three-bythree quadrats) of trees estimated by spatial autocorrelation. Of the 326 data sets tested, 299 converged when using the LCOR program and resulted in meaningful output. Overall aggregation was prevalent at this spatial hierarchy with $252 / 299=84.3 \%$ of the orchard blocks, indicating aggregation. The core cluster size (number of adjacent significant lag positions) ranged from 0 to 264. There was a direct relationship of increasing core cluster size and the $D$ category with average core cluster size (Table 1; Fig. 4A). The strength of aggregation associated with the spatial autocorrelation analyses also increased with the $D$ category with average strength of aggregation and often was associated with an asymmetry of the core cluster (Table 1; Fig. 4B). In the majority of cases, core clusters were incomplete (i.e., unsaturated with significant positive lags). However, the greatest magnitude for strength of aggregation was associated with the category $D>3.5$, and many of the core clusters were saturated or nearly so, indicating compact aggregation of $X$. axonopodis pv. citridiseased trees. Reflected clusters were indicated in $187 / 299=$ $62.5 \%$ of tests. The maximum reflected cluster size (largest
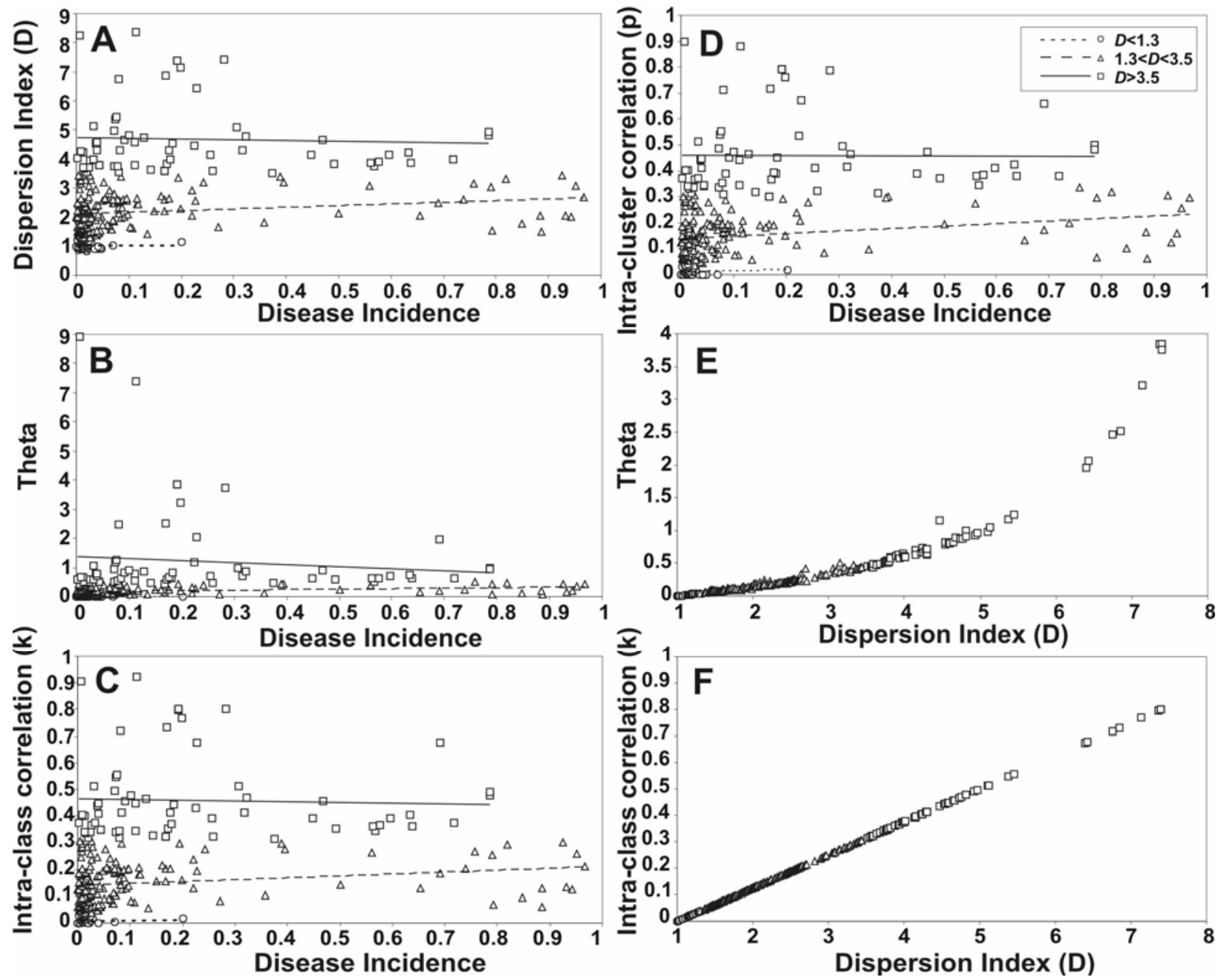

Fig. 2. $\beta$-Binominal analysis at the within-quadrat scale of 321 orchards infected with citrus canker in Sao Paulo state, Brazil, demonstrating the relationship of the $\mathbf{A}$, dispersion index, B, Theta, $\mathbf{C}$, intraclass correlation $(k)$, and $\mathbf{D}$, intracluster correlation $(p)$, each as a function of disease incidence; and the relationship of $\mathbf{E}$, Theta and $\mathbf{F}$, intraclass correlation $(k)$ to dispersion index $(D)$. Graph illustrates the dispersal of data sets by their relative dispersion index $D$ value $(D<1.3,1.3 \leq$ $D \leq 3.5$, and $D>3.5$ ). 
grouping of SL+ positions), number of reflected clusters, and average distance between core and reflected cluster centroids in spatial lag units also increased with $D$ (Table 1; Fig. 4C and D), indicating an associated and increasing average distance in tree spaces between core and reflected clusters. Thus, as $D$ increased, aggregation became more compact and the distance between clusters increased. Average within-row, across-row, and edgeeffects parameters estimated as the number of SL+ positions and their associated standard deviations demonstrated that within-row aggregation generally was stronger than across-row, indicating a more general prevalence of disease and foci that were more extensive in the within-row orientation, where trees generally were more closely spaced (Table 1; Fig. 4F-H). When edge effects were detected, they generally were not significant; that is, the proportion of SL+ positions at the distal edges of the proximity pattern were generally $<5 \%$, indicating a lack of significance.

Reoccurrence of ACC in plantings subjected to eradication. The frequency distribution of counts of $X$. axonopodis pv. citriinfected trees that occurred at various distance categories can be considered a generalized dispersal gradient. The citrus canker-
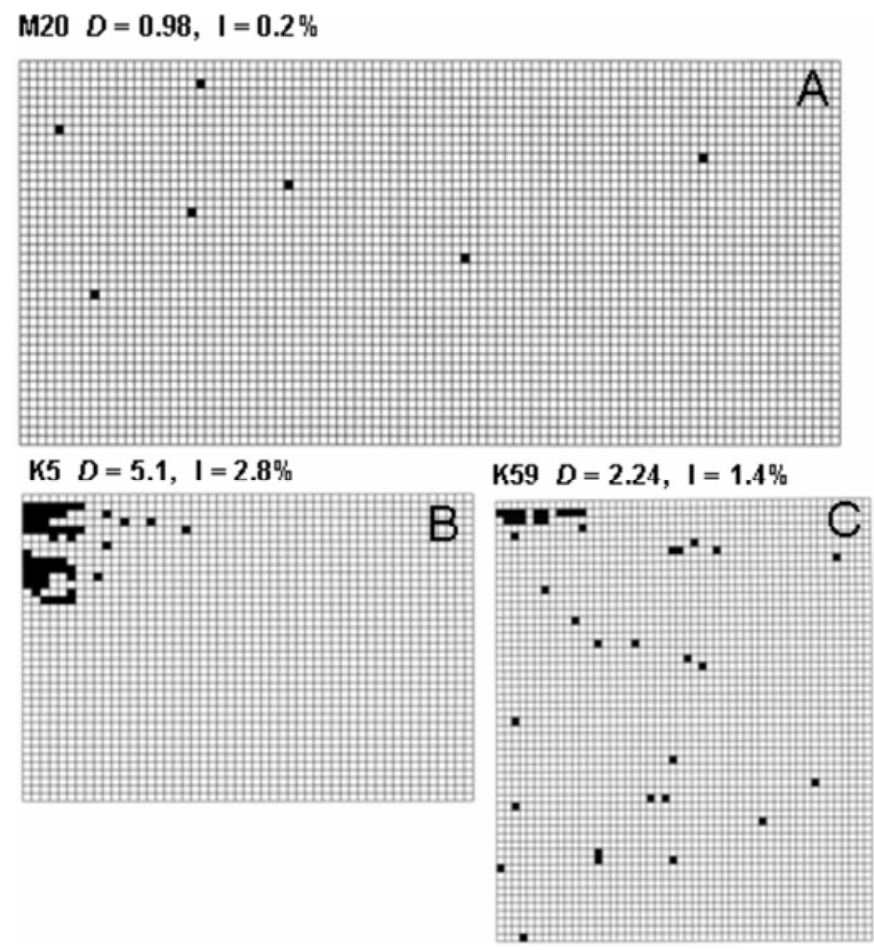

Fig. 3. Representative maps of canker infected citrus orchards representing various categories of the dispersion index $D$. A, $D<1.3, \mathbf{B}, 1.3 \leq D \leq 3.5$, and C, $D>3.5$. infected tree gradient in São Paulo decreased over distance and was well described by an inverse power law function, $y=$ $31413.5 x^{-1.186}, R^{2}=0.983$, where $y=$ disease incidence and $x=$ distance in meters. In São Paulo, the calculated cumulative distribution of the frequency of counts of $X$. axonopodis pv. citriinfected plants (i.e., the cumulative percentage of the $X$. axonopodis pv. citri-infected population) over distance was described well by the monomolecular model, $y=\{1-(0.79) \times$ $\exp [-(0.007) \times x]\}, R^{2}=0.999$ (Fig. 5A and B). Utilizing the above monomolecular model on the São Paulo data, the distances necessary to circumscribe 90,95 , and $99 \%$ of the new diseased trees that occurred were 296, 396, and $623 \mathrm{~m}$, respectively. The functions and distances for São Paulo were found to be very similar to the distances circumscribing 90,95 , and $99 \%$ of the new diseased trees in residential areas in southeast Florida. The distances for residential areas in Florida were $213 \mathrm{~m}$ (range 152 to $613 \mathrm{~m}$ ), $335 \mathrm{~m}$ (range 213 to $773 \mathrm{~m}$ ), and $594 \mathrm{~m}$ (range 427 to $899 \mathrm{~m})$, respectively.

\section{DISCUSSION}

Four quantitative tools were used to assess the spatial arrangement and heterogeneity associated with $X$. axonopodis $\mathrm{pv}$. citri-infected trees at different spatial hierarchies. Binomial analysis was utilized to assess individual orchards for local aggregation at the within-group spatial scale within three-bythree-tree quadrats. Examination of the results of the binomial analyses of 321 orchards resulted in the parsing of the orchards into three categories based on the magnitude of each orchard's binomial index of dispersion, $D(D<1.3,1.3 \leq D \leq 3.5$, and $D>$ $3.5)$. The $D$ value associated with each individual orchard in the population was used for identification and carried through additional analyses at other spatial hierarchies. This association with the $D$ value was used for comparative purposes to maintain an indication of orchard heterogeneity at one spatial scale when examining the heterogeneity and other spatial characteristics at additional spatial hierarchies.

To examine the heterogeneity of $X$. axonopodis pv. citriinfected trees at the three-by-three tree or group scale across the entire population of orchards, the binary form of the Taylor's power law was applied. The entire population of 321 orchards was well described by one analysis. For the entire population, the $\log (A)$ constant was significantly $>0$ and the $b$ constant was significantly $>1$, indicating that the population as a whole displayed overdispersion or aggregation and this aggregation varied with disease incidence. For closer examination, the population was parsed into the three categories based on $D$ value: $D<1.3,1.3 \leq D \leq 3.5$, and $D>3.5$. For all three categories, the $\log (A)$ constant was significantly $>0$ and $b$ was significantly $>1.0$. However, within the first category $(D<1.3)$, some orchards lacked aggregation. The second and third categories $(1.3 \leq D \leq$

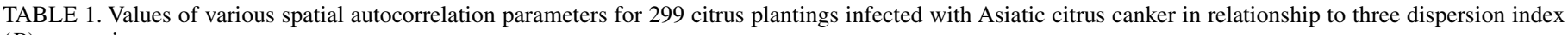
(D) categories

\begin{tabular}{|c|c|c|c|}
\hline \multirow[b]{2}{*}{ Spatial autocorrelation parameter ${ }^{\mathrm{a}}$} & \multicolumn{3}{|c|}{ Disease dispersion index $(D)^{\mathrm{b}}$} \\
\hline & $D<1.3$ & $1.3 \leq D \leq 3.5$ & $D>3.5$ \\
\hline Core cluster size $(\mathrm{SL}+)$ & $2.36 \pm 2.91$ & $7.47 \pm 12.64$ & $34.63+45.64$ \\
\hline Average strength of aggregation & $0.228 \pm 0.373$ & $0.704 \pm 0.379$ & $0.927 \pm 0.214$ \\
\hline Maximum reflected cluster size (quadrats) & $1.56+0.94$ & $2.39+2.71$ & $3.10+1.53$ \\
\hline Number of reflected clusters (quadrats) & $5.0 \pm 1.4$ & $10.0 \pm 1.4$ & $3.0+0.6$ \\
\hline Average distance between core and reflected clusters (Lags) & $6.05 \pm 3.04$ & $7.44+4.62$ & $11.20 \pm 6.66$ \\
\hline Average distance between core and reflected clusters (tree spaces) & 18.15 & 22.32 & 33.60 \\
\hline Within row effects $(\mathrm{SL}+)$ & $0.88 \pm 1.16$ & $0.43 \pm 0.76$ & $1.27 \pm 0.60$ \\
\hline Across row effects (SL +$)$ & $2.26 \pm 2.52$ & $1.22 \pm 1.74$ & $1.80 \pm 1.31$ \\
\hline Edge effects (SL+) & $5.70 \pm 4.56$ & $3.55 \pm 3.52$ & $4.96 \pm 2.59$ \\
\hline
\end{tabular}

${ }^{\text {a }}$ For spatial autocorrelation analysis, data for each citrus block was parsed into three-by-three-tree quadrats.

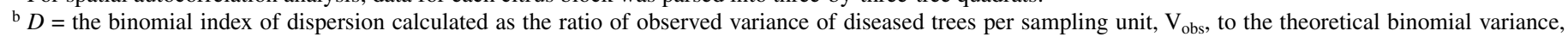
$\mathrm{V}_{\text {bin. }}$. Values of $D>1.0$ are considered indicative of heterogeneity (i.e., aggregation within the data set). Values are presented as means \pm standard deviation. 
3.5 and $D>3.5$ ) represented portions of the population in which all orchards expressed aggregation, and the degree of aggregation related to disease incidence.

Although the binomial analysis and Taylor's power law provide excellent assessments of the spatial structure of a population at the group level, they do not give any information about the population of foci within an orchard that are contributing to an assessment of random distribution versus overdispersion. For instance, for an individual orchard, if overdispersion is indicated, we do not know if that overdispersion is indicative of a single
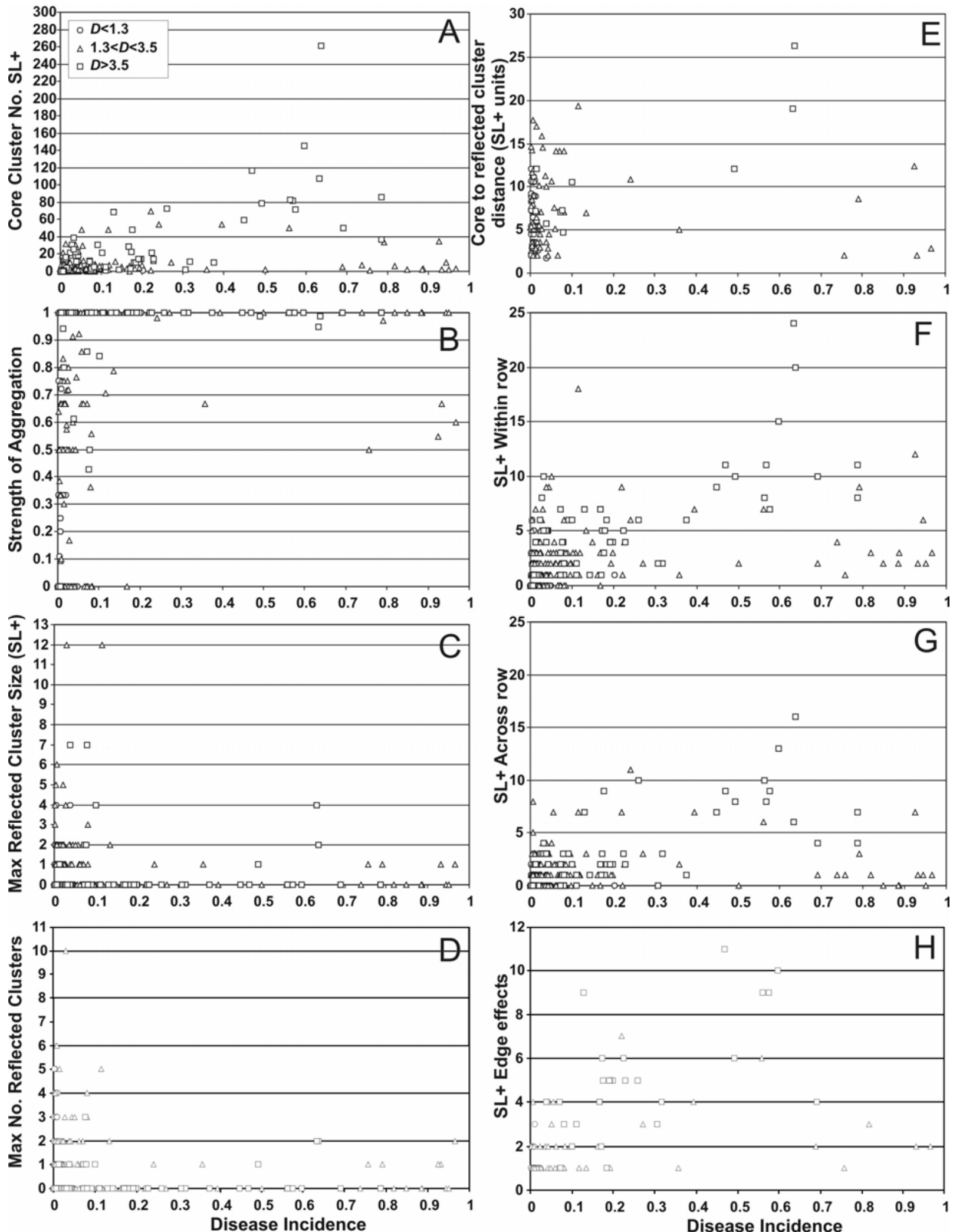

Fig. 4. Spatial autocorrelation analysis at the among-quadrat scale for 299 orchards infected with citrus canker in Sao Paulo state, Brazil. A, Relationship between increasing core cluster size and disease incidence. B, Relationship between spatial autocorrelation strength of aggregation and disease incidence. C, Relationship between maximum reflected cluster size and disease incidence. D, Relationship between maximum number of reflected clusters and disease incidence. E, Relationship between core to reflected cluster distance and disease incidence. F-H, Relationship between average within row, across row, and edge effects and disease incidence. 
focus or multiple foci of disease. To examine this characteristic of aggregation, the calculated number of foci per 1,000 trees was used. For the composite population of 321 orchards, the trend was for the number of foci per 1,000 to increase with disease incidence until disease incidence reached 0.2 to 0.3 ; then, the trend was for the number of foci to decrease over the remainder of the disease incidence range. However, when we examine the same information parsed into the three categories based on $D$ value, we see separate and more distinctive trends. For the first category, there was a rapid and more or less linear increase in the number of foci per 1,000 trees up to a maximum of 70 foci and the population was restricted to disease incidence $<0.2$. For the second category, the trend was similar to the entire population, but with an improved fit to the trend as described by the $\beta$ function over the entire range of disease incidence (0.01 to 1.0$)$, and the greatest number of foci per 1,000 trees ( 72 foci) was found at a disease incidence of $\approx 0.21$. For the third category, the number of foci per 1,000 trees never exceeded 35 and disease incidence did not exceed 0.8 . This trend is reflected by the $\beta$ function that describes the trend in the number of foci over the range of disease incidence (Fig. 1F) although, for citrus canker in Brazil, that peak of aggregation, as expressed by the number of discrete foci, appears to be shifted toward the lower end of the disease incidence range. This most likely is due to individual canker infections that are not uniformly distributed throughout an orchard, but are in a higher concentration in some areas of the orchard compared with other areas and, thus, are closer together. As these individual foci of $X$. axonopodis pv. citri-infected trees increase in size, they will begin to coalesce at lower disease incidence levels due to their close proximity to one another.

When we examine the spatial autocorrelation analysis results, we are looking at the relationship among groups of $X$. axonopodis
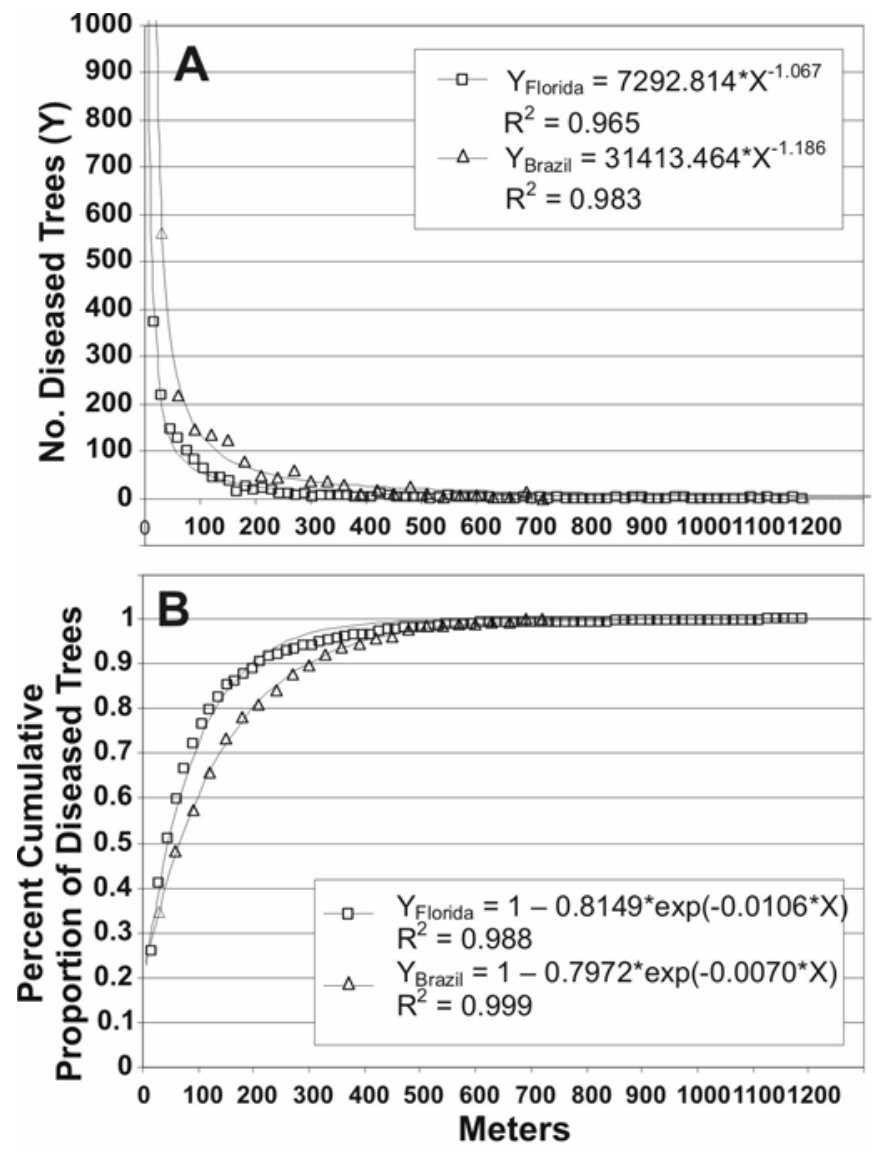

Fig. 5. Disease gradients and frequency distributions of occurrence of new infections of citrus canker in Brazil and Florida. A, Disease gradients fit to an Inverse Power Law model. B, Cumulative frequency distributions of the proportion of diseased trees by distance. pv. citri-infected trees or foci. We see that there was a prevalence of core clusters of SL+ positions that was quite extensive even at low disease incidence (Fig. 4A); these core clusters often were not saturated (Fig. 4B) and reflected clusters often existed (some of considerable size) (Fig. 4C and D). This is supportive of the conclusion that there are a large number of foci that occur relatively close together at low incidence levels. The average core-toreflected-cluster distance also increased with $D$ value (Fig. 4E), indicating a coalescence of foci closer together as disease incidence increases, resulting in fewer remaining and larger foci residing at greater distances and at higher disease incidence levels.

The Asian leafminer was discovered in Florida in 1993 and in Brazil in 1996. With its introduction, the pathosystem was complete in both countries as it exists in southeastern Asia, the ancestral home of citrus, citrus canker, and the leafminer. Prior to the introduction of the Asian leafminer, citrus canker was most often found in highly aggregated foci (10). The insect rapidly spread across citrus-growing regions in both areas and resulted in tremendous damage to new growth flushes that often involved most of the leaves on a flush infested. Following its introduction, the number of orchards with more diffuse distributions of $X$. axonopodis pv. citri-infected trees rose sharply in both countries, as seen within the collection of 321 orchard maps examined in this study. To understand how the leafminer might affect such a dramatic shift in spatial pattern of citrus canker, we first must examine its effect on the infection process. First, the leafminer exposes the mesophyll of the leaf lamina to potential infection during the formation of feeding galleries which are covered with a delicate, damaged, cracked, and incomplete cuticle (Fig. 6). The leafminer-exposed mesophyll also resists callus formation to protect it and remains callus free for $\approx 14$ days, compared with 1 to 2 days for mechanically induced wounds $(1,20,22)$. This results in large amounts of foliar, green stem, and occasionally fruit tissues with prolonged exposure to bacterial infection. Prior to the introduction of the leafminer, citrus mesophyll tissues rarely would be exposed to direct infection except when mechanically damaged and such wounds would callus quickly. Citrus canker spreads naturally via wind-blown rain $(10,14,38,39)$. Unless the $X$. axonopodis pv. citri bacteria come in contact with mesophyll tissues exposed by wounds during the short time period prior to callus formation, the only infection that occurs is through stomatal infection. In this case, bacteria are driven through the stomata when bacteria-laden rain droplets are combined with wind speeds $>8.0 \mathrm{~m} / \mathrm{s}$, and into the substomatal chambers where they begin to propagate. Above this wind speed threshold, water congestion of foliar tissues occurs, forming a continuous column

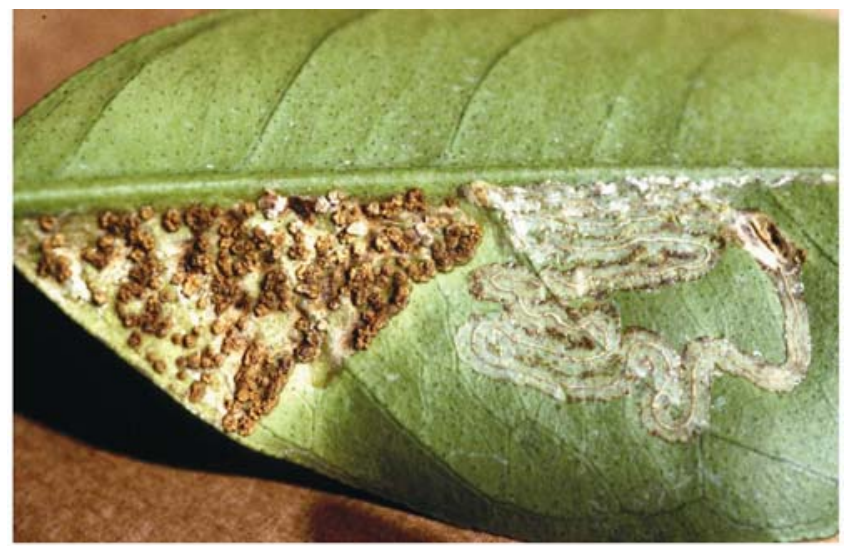

Fig. 6. Canker and Asian leafminer interaction. Leafminer feeding gallery on left compared with similar gallery that has become infected with Xanthomonas axonopodis pv. citri on right. Leafminer provides wounds that expose the leaf mesophyll tissues to infection, greatly exacerbating the number of citrus canker infections and, thus, inoculum production. Note no infection in areas lacking leafminer damage. 
of water from the substomatal chamber through the stomata to the phylloplane surface (38). Inoculum-laden rain water is easily forced through the stomata above this wind speed $(8,22)$. However, when leafminer wounds are prevalent, water congestion is not necessary and inoculum-laden rain simply coming to rest on a leafminer gallery easily passes through the damaged and cracked cuticle and comes in direct contact with the highly susceptible, exposed, and noncallused mesophyll cells. In addition, leafminer larvae can come in contact with the inoculum and spread it throughout the feeding gallery, resulting in hundreds of infections per gallery (Fig. 6). Many cultivars that have a general field resistance to citrus canker become susceptible in the field due to leafminer that exposes the foliar mesophyll to prolonged infection (9). Compared with the relatively few stomatal infections that normally occur per leaf, $X$. axonopodis pv. citri infections in leafminer galleries can produce tremendous amounts of inoculum, perhaps as much as a $10^{3}$ - to $10^{4}$-fold more inoculum than when leafminer is not present (2).

Thus, the presence of the leafminer facilitates the $X$. axonopodis pv. citri infection process and subsequent inoculum production. Cells of $X$. axonopodis pv. citri have relatively poor survival and are short lived on plant surfaces $(21,23)$; therefore, in the absence of leafminer infestation, mild rainstorms with winds $<8 \mathrm{~m} / \mathrm{s}$ would result in few infections because the $X$. axonopodis pv. citri inoculum landing on plant surfaces could not penetrate the cuticle and would simply die on the leaf surface. However, with the leafminer present, rain combined with gentle to hurricane velocity winds can carry inoculum that can be deposited on foliar surfaces and penetrate the plethora of leafminer galleries, resulting in many-fold more infections. When this is combined with the vastly increased, leafminer-induced inoculum generation, the rate of disease increase rises sharply.

In addition, the presence of the numerous highly susceptible infection courts resulting from leafminer wounds that remain susceptible for prolonged periods has an indirect effect on spatial patterns of citrus canker disease. Consider a mild rain shower combined with winds $<8 \mathrm{~m} / \mathrm{s}$. Inoculum oozes to the surfaces of canker lesions within a few minutes after the lesions become wet $(3,42)$. This inoculum is water splashed and incorporated into drops and droplets of varying size. Smaller droplets, especially, can be picked up in air currents and moved considerable distances $(14,17,18,41)$. In the absence of leafminer wounds, the vast majority of this inoculum that falls on citrus tissues would not penetrate the cuticle. However, when the leafminer is present, the inoculum concentration is much higher and bacteria-laden droplets landing on the prodigious leafminer galleries (wounds) can result in numerous infections. Thus, even gentle storms can result in many-fold more infections over the entire bacterial inoculum dispersal range without the need for water congestion for infection. With the leafminer present, even though inoculum may be very sparse, as within the tail end of the dispersal gradient, infection is more probable. We see this demonstrated in the initial patterns of citrus canker in orchards with very low disease incidence as a nearly random distribution pattern of disease (Fig. 3). In the past, prior to the presence of the leafminer, such isolated infections soon would have resulted in more compact and highly aggregated foci of infection. However, the presence of the leafminer results in a more extensive dispersal gradient with more infections, increasing the number of foci per planting and the dispersal from planting to planting.

The change in citrus canker disease dynamics following the leafminer introduction has necessitated changes in the citrus canker eradication program procedures in both Brazil and Florida. Prior to the introduction of the leafminer, eradication in Brazil was centered around a 30-m regulation that dictated removal of all $X$. axonopodis pv. citri-exposed trees within $30 \mathrm{~m}$ of a known infected tree based on the study of dispersal gradients following rainstorms in Argentina (41). The latent period for citrus canker is $\approx 10$ to 14 days for the first small but visible symptoms to develop $(12,37)$. However, under orchard conditions, lesions often need to progress for several weeks and additional within-tree infection cycles may need to occur before the disease manifests itself sufficiently for visual detection. In Florida, maximum visual detection was determined to be $\approx 107$ days post infection (17). The $30-\mathrm{m}$ eradication distance used in Brazil takes into account the latency period and difficulty of detection of "subclinical" (below visual detection threshold) infections by removing a group of trees surrounding infected trees within which subclinical infections are highly probable. Similarly, in Florida prior to 2000, a $125-\mathrm{ft}$ regulation dictated the removal of all $X$. axonopodis pv. citri-exposed trees within $38 \mathrm{~m}(125 \mathrm{ft})$ of an infected tree based on the same Argentine study.

In Florida, following the introduction of the Asian leafminer, the $125-\mathrm{ft}$ protocol became decreasingly effective through time, prompting the CCEP to request a study to examine distances of spread of citrus canker in urban areas (17). Similarly, in Brazil, continued reoccurrence of ACC in citrus plantings previously subjected to eradication indicated that the current method of removing all trees within a $30-\mathrm{m}$ radius of known $X$. axonopodis pv. citri-infected trees was insufficient to eradicate the disease within infected orchards, allowing numerous escapes beyond the 30-m distance. Data collected by the eradication project indicated that, often, numerous repeated application of the 30-m removal protocol did not eradicate the infection in individual plantings. The calculated distances necessary to remove 90,95 , and $99 \%$ of the population of new infected trees in citrus plantings in Brazil reported in this study were remarkably similar to distances found necessary to remove the same proportions of the population in residential areas in south Florida (17). The average distances calculated from the Brazilian data of 100 citrus plantations fall within the range of those calculated from the five urban study sites in Florida $(13,17)$. This indicates that the same spatial processes that affected the spread of $X$. axonopodis pv. citri in Florida likely affected the pathogen's spread in Brazil as well. Both of these studies are consistent with and fell within the same distance ranges observed in a prior study of $X$. axonopodis pv. citri spread in a commercial grove in south-central Florida; however, in the latter case, only very few (four) indications of such long-distance dispersal were seen (10) (Fig. 5). This would indicate that the dispersal mechanism has not changed but the quantity of inoculum produced and the likelihood of infection at the end of the dispersal tail have both increased. The postleafminer-introduction change in $X$. axonopodis pv. citripathosystem dynamics resulted in the adoption of the 1,900-ft law in Florida that modified the eradication protocol by requiring removal of all trees within $579 \mathrm{~m}(1,900 \mathrm{ft})$ of known $X$. axonopodis pv. citri-infected trees in an attempt to remove the majority ( 95 to $99 \%$ ) of the exposed and subclinically diseased trees $(13,17)$. In Brazil, the corroborating data was utilized slightly differently. Knowing that the $30-\mathrm{m}$ eradication protocol was not always sufficient to achieve eradication, a new protocol was developed based on a combination of distance and disease incidence. In the State of São Paulo, Brazil, the citrus canker eradication program personnel first assess an infected planting to determine its associated disease incidence. If disease incidence is $\leq 0.005$, then the $30-\mathrm{m}$ protocol is applied as has been done historically. However, if the disease incidence is $>0.005$, then all trees within the planting are destroyed. Thus, depending on planting size and disease incidence, the Brazilian canker eradication protocols are at times less stringent and at times more stringent than the now-discontinued Florida eradication protocol.

\section{ACKNOWLEDGMENTS}

We thank the many disease surveyors and officials in the Citrus Canker Eradication Program in the state of São Paulo, Brazil, and Fundecitrus for 
providing the maps of citrus canker disease and for dedicating large amounts of time, manpower, and effort toward this study; and J. Taylor for performing the large number of individual statistical analyses for each data set summarized in this presentation.

\section{LITERATURE CITED}

1. Belasque Jr., J., Para-Pedrazzoli, A. L., Rodrigues Neto, J., Yamamoto, P. T., Chagas, M. C. M., Parra, J. R. P., Vinyard, B. T., and Hartung, J. S. 2005. Adult citrus leafminers (Phyllocnistis citrella) are not efficient vectors of Xanthomonas axonopodis pv. citri. Plant Dis. 89:590-594.

2. Bergamin-Filho, A., Amorim, L., Laranjeira, F. F., and Gottwald, T. 2000. Epidemiology of citrus canker in Brazil with and without leafminer. Proc. Int. Workshop on Citrus Canker. Online. Publication no. 2000/0620 bergamin-filho.

3. Bock, C. H., Parker, P. E., and Gottwald, T. R. 2005. Effect of simulated wind-driven rain on duration and distance of dispersal of Xanthomonas axonopodis pv. citri from canker infected citrus trees. Plant Dis. 89:71-80.

4. Braithwaite, M., Leite, R. P., Smith, J. J., Boa E., and. Saddler, G. S. 2002. First report of citrus canker caused by Xanthomonas campestris pv. citri on Citrus sinensis in Bolivia. Plant Pathol. 51:383.

5. Campbell, C. L., and Madden, L. V. 1990. Introduction to Plant Disease Epidemiology. John Wiley \& Sons, New York.

6. Danos, E., Berger, R. D., and Stall, R. E. 1984. Temporal and spatial spread of citrus canker within groves. Phytopathology 74:904-908.

7. Gottwald, T. R., Garnsey, S. M., and Borbón, J. 1998. Increase and patterns of spread of citrus tristeza virus infections in Costa Rica and the Dominican Republic in the presence of the brown citrus aphid, Toxoptera citricida. Phytopathology 88:621-636.

8. Gottwald, T. R., and Graham, J. H. 1992. A device for precise and nondisruptive stomatal inoculation of leaf tissue with bacterial pathogens. Phytopathology 82:930-935.

9. Gottwald, T. R., Graham, J. H., Civerolo, E. L., Barrett, H. C., and Hearn, C. J. 1993. Differential host range reaction of citrus and citrus relatives to citrus canker and citrus bacterial spot determined by leaf mesophyll susceptibility. Plant Dis. 77:1004-1009.

10. Gottwald, T. R., Graham, J. H., and Egel, D. S. 1992. Analysis of foci of Asiatic citrus canker in a Florida citrus orchard. Plant Dis. 76:389-396.

11. Gottwald, T. R., Graham, J. H., and Schubert, T. S. 1997. An epidemiological analysis of the spread of citrus canker in urban Miami, Florida, and synergistic interaction with the Asian citrus leafminer. Fruits 52:383-390.

12. Gottwald, T. R., Graham, J. H., and Schubert, T. S. 2002. Citrus Canker: The pathogen and its impact. Plant Health Progress doi:10.1094/PHP2002-0812-01-RV.

13. Gottwald, T. R., Hughes, G., Graham, J. H., Sun, X., and Riley, T. 2001. The citrus canker epidemic in Florida: the scientific basis of regulatory eradication policy for an invasive species. Phytopathology 91:30-34.

14. Gottwald, T. R., McGuire, R. G., and Garran, S. 1988. Asiatic citrus canker: spatial and temporal spread in simulated new planting situations in Argentina. Phytopathology 78:739-745.

15. Gottwald, T. R., Reynolds, K. M., Campbell, C. L., and Timmer, L. W. 1992. Spatial and spatiotemporal autocorrelation analysis of citrus canker epidemics in citrus nurseries and groves in Argentina. Phytopathology 82:843-851.

16. Gottwald, T. R., Richie, S. M., and Campbell, C. L. 1992. LCOR2Spatial correlation analysis software for the personal computer. Plant Dis. 76:213-215.

17. Gottwald, T. R., Sun, X., Riley, T. D., Graham, J. H., Ferrandino, F., and Taylor, E. L. 2001. Geo-referenced, spatiotemporal analysis of the urban citrus canker epidemic in Florida. Phytopathology. 92:361-377.

18. Gottwald, T. R, Timmer, L. W., and McGuire, R. G. 1989. Analysis of disease progress of citrus canker in nurseries in Argentina. Phytopathology 79:1276-1283.

19. Graham J. H, and Gottwald, T. R. 1991. Research perspectives on eradication of citrus bacterial diseases in Florida. Plant Dis. 75:1193-1200.

20. Graham, J. H., Gottwald, T. R., Browning, H. W., and Achor, D. S. 1996. Citrus leaf minor exacerbated the outbreak of Asiatic citrus canker in South Florida. Page 83 in: Proc. Int. Work Conf. "Managing the citrus leaf minor." Univ. of Florida, Gainesville.
21. Graham, J. H., Gottwald, T. R., Cubero, J., and Achor, D. 2004. Xanthomonas axonopodus pv. citri: Factors affecting successful eradication of citrus canker. Mol. Plant Pathol. 5:1-15.

22. Graham J. H., Gottwald, T. R., Riley, T. D., and Achor, D. 1992. Penetration through leaf stomata and growth of strains of Xanthomonas campestris in citrus cultivars varying in susceptibility to bacterial diseases. Phytopathology 82:1319-1325.

23. Graham, J. H., Gottwald, T. R., Riley, T. D., Cubero, J., and Drouillard, D. L. 2000. Survival of Xanthomonas campestris pv. citri (Xcc) on various surfaces and chemical control of Asiatic citrus canker (ACC). Proc. Int. Workshop on Citrus Canker. Online. Publication no. 2000/0620graham.

24. Hau, B., and Kranz, J. 1990. Mathematics and statistics for analyses in epidemiology. Pages 12-52 in: Epidemics of Plant Diseases. J. Kranz, ed. Springer, Berlin.

25. Hogg, D. R. 1985. Citrus canker in Argentina: A case history. Pages 8-10 in: Citrus Canker: An International Perspective. L. W. Timmer, ed. Citrus Research and Education Center, University of Florida, Lake Alfred.

26. Hughes, G., and Madden, L. V. 1992. Aggregation and incidence of disease. Plant Pathol. 41:657-660.

27. Hughes, G., and Madden, L. V. 1993. Using the beta-binomial distribution to describe aggregated patterns of disease incidence. Phytopathology 83:759-763.

28. Koizumi, M. 1977. Factors related to the occurrence of spring canker [in citrus] caused by Xanthomonas citri (Hasse) Dowson. Proc. Int. Soc. Citric. 3:924-928. Intl. Soc. Citriculture, Lake Alfred, Fl.

29. Koizumi, M. 1985. Citrus canker: the world situation. Pages 2-7 in: Citrus Canker: An International Perspective. L. W. Timmer, ed. University of Florida, Lake Alfred.

30. Madden, L. V. 1989. Dynamic nature of within-field disease and pathogen distributions. Pages 96-126 in: Spatial Components of Plant Disease Epidemics. M. J. Jeger, ed. Prentice-Hall, Englewood Cliffs, NJ.

31. Madden, L. V., and Hughes, G. 1995. Plant disease incidence: distributions, heterogeneity, and temporal analysis. Annu. Rev. Phytopathol. 33:529-564.

32. Madden, L. V., and Hughes, G. 1999. An effective sample size for predicting plant disease incidence in a spatial hierarchy. Phytopathology 89:770-781.

33. Madden, L. V., Nault, L. R., Murral, D. J., and Apelt, M. R. 1995. Spatial pattern analysis of the incidence of aster yellows disease in lettuce. Res. Popul. Ecol. 37:279-289.

34. Madden, L. V., Reynolds, K. M., Pirone, T. P., and Raccah, B. 1988. Modeling of tobacco virus epidemics as spatio-temporal autoregressive moving-average processes. Phytopathology 78:1361-1366.

35. Pruvost, O., Gottwald, T. R., and Brocherieux, C. 1999. The effect of irrigation practices on the spatio-temporal increase of Asiatic citrus canker in simulated nursery plots in Reunion Island. Eur. J. Plant Pathol. 105:23-37.

36. Reynolds, K. M., and Madden, L. V. 1988. Analysis of epidemics using spatio-temporal autocorrelation. Phytopathology 78:246-252.

37. Schubert, J., Rizvi, S. A. , Sun, X., Gottwald, T. R., Graham, J. H., and Dixon, W.N. 2001. Meeting the challenge of eradicating citrus canker in Florida-again. Plant Dis. 85:340-356.

38. Serizawa, S., and Inoue, K. 1974. Studies on citrus canker, Xanthomonas citri. III. The influence of wind on the infection of citrus canker. Bull. Schizuoka Pref. Citrus Exp. Stn. 11:54-67.

39. Serizawa, S., Inoue, K., and Goto, M. 1969. Studies on citrus canker I. Dispersal of the citrus canker organism. Bull. Schizuoka Pref. Citrus Exp. Stn. 8: 81-5.

40. Stall, R. E., and Civerolo, E. L. 1991. Research relating to the recent outbreak of citrus canker in Florida. Annu. Rev. Phytopathol. 29:399420.

41. Stall, R. E., Miller J. W., Marco, G. M., and Echenique, B. I. C. 1980. Population dynamics of Xanthomonas citri causing cancrosis of citrus in Argentina. Proc. Annu. Meet. Fla. State Hortic. Soc. 93:10-14.

42. Timmer, L. W., Gottwald, T. R., and Zitco, S. E. 1991. Bacterial exudation from lesions of Asiatic citrus canker and citrus bacterial spot. Plant Dis. 75:192-195.

43. Upton, G., and Fingleton, B. 1985. Spatial Data Analysis by Example, Vol. 1. Point Pattern and Quantitative Data. John Wiley \& Sons, Chichester, West Sussex, England. 